\title{
Computer-Aided Design System Development of Fixed Water Distribution of Pipe Irrigation System
}

\author{
Mingyao Zhou*, Susheng Wang, Zhen Zhang, and Lidong Chen \\ College of Hydraulic Science and Engineering, Yangzhou University, \\ 31 middle Jiangyang Rord, Yangzhou 225009, Jiangsu Province, P.R. China \\ Tel.: +86-514-87978640; Fax: +86-514-87978640 \\ myzhouyz@163.com
}

\begin{abstract}
It is necessary to research a cheap and simple fixed water distribution device according to the current situation of the technology of low-pressure pipe irrigation. This article proposed a fixed water distribution device with round table based on the analysis of the hydraulic characteristics of low-pressure pipe irrigation systems. The simulation of FLUENT and GAMBIT software conducted that the flow of this structure was steady with a low head loss comparing to other types of devices. In order to improve the design efficiency, a program was made using Visual Basic. The system was user-friendly, flexible operation, convenient and able to meet the needs of different users.
\end{abstract}

Keywords: pipeline; irrigation; fixed water distribution device; ComputerAided.

\section{Introduction}

As the economy developed speedy, the contradiction between the water use of industry, agriculture and life will be more prominent. So developing water saving agriculture comes to be an important measure to the contradiction and to improve the grain yield (Department of Rural Water Resources in Ministry of water resources, 1998; Yuanhua Li et al., 1999; Ligui Xie et al., 2001). The low-pressure pipeline irrigation system is a new water saving and energy saving irrigation system in our country these years. It proved to be saving water more than $40 \%$, energy $20 \sim 30 \%$, and land $2 \sim 4 \%$. With the significant benefits and broad prospect, the low-pressure pipeline irrigation has been becoming the major trends of water saving irrigation project(Department of Science and Education in Ministry of water resources, 1991).

Water gaging equipment and technology is the basic measure to plan the water using and to control the irrigation quality. It can not make the water arrangement of every plot accurate without water gaging equipment, though the recent water distribution devices have the control ability. So developing the fixed water distribution device of the pipeline system is necessary to adapt to the field irrigation management, and provide instantly accurate water allocation(Shuangen Yu et al., 2004). Water

\footnotetext{
* Corresponding author.
} 
distribution device contains tee, standpipe and hydrant, but the research on fixed water distribution device of pipeline is still relatively few(Xiao Li et al., 1996; Qingfeng Ji et al., 2001; Changde Wang, 2005). Considering the economic, reasonable and operational factors, this article discussed the fixed water distribution device with round table based on the comparison and analysis of current hydrant(Qingseng $\mathrm{He}$ et al., 1992; Jiesheng Huang et al., 1998; Zhengrong Huang et al., 2001; Liguo Ming et al., 2002).

\section{Structure Design of Fixed Water Distribution Device with Round Table}

\subsection{The Principle of Operation}

From the comparison and analysis, we chose the adjustable fixed water distribution device with spring structure. The structure is shown in Fig.1.

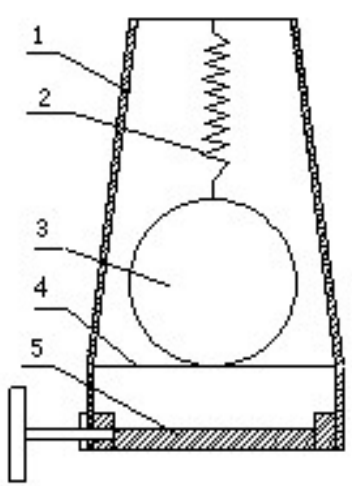

Fig. 1. Fixed water distribution device with round table 1-shell; 2-spring; 3-ball valve; 4-ball bar; 5-butterfly valve

The bottom of the water distribution device is controlled by butterfly valve. When the pipeline works, the butterfly valve is opened, and the spring becomes deformed under the impulse of water flow. The deformation is larger as the water pressure is higher, and the ball goes to the upper part of the device. For the special structure of the round table, the area of flow comes down and the flow rate stays steady. And vice versa.

\subsection{Design of the Structure Dimension}

Because of the water impulse force, the ball will be at different places. If we want the flow rate maintain steady, the area of flow should be corresponding to the water pressure. This can be put into practice by the structure of round table. The structure dimension is shown in Fig.2. 
In Fig. $2, r_{1}$ is the radius of the ball, $r$ and $R$ is the radius of the top and the bottom of the round table, $R_{1}$ is the radius at the position of flow area, and $\mathrm{h}$ is height of the round table. The structure dimension design can be divided into three steps:

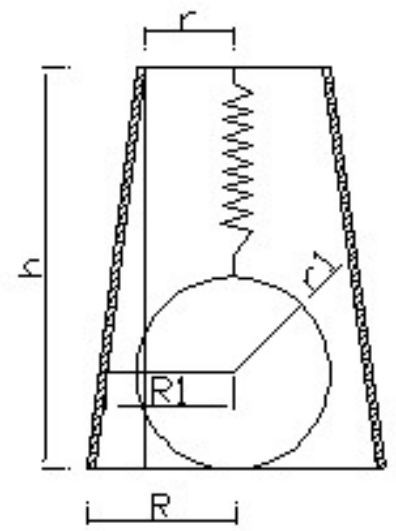

Fig. 2. Structure dimension of the device

First, set the ball radius, then calculate $R_{1}$ by (1).

$$
R_{1}=\sqrt{\frac{A}{\pi}}+r_{1}
$$

Second, make certain the height of the round table combining the standpipe.

Finally, calculate $r$ and $R$. It should be in the standard pipe size, in order that it is propitious to manufacture and install.

In additional, the top and bottom of the round table need to meet the conditions as follows:

(1)The area of the top is greater than the minimal flow area of the device.

(2)There is a differential between the area of the top and the bottom, so the flow area can change as the ball moving.

(3)There should not be a huge difference between the radius of the bottom and the standpipe, or it is easy to damage and hard to install.

\subsection{Design of the Spring}

It made a simple treatment when design the spring. The spring was thought to be a uniform elastic rod and it only did one-dimensional longitudinal vibration(Zhilun Xu, 2002). When the spring interacted to other objects, it followed the Hooke's law. So Hooke's law became the starting point of the spring problem. The analysis of the ball's force balance is shown in Fig.3. 


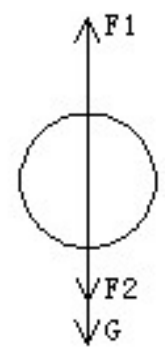

Fig. 3. Force analysis of the ball

In Fig. 3, $F_{1}$ is the water impulse force, $F_{2}$ is the elastic force, and $G$ is the ball's gravity.

$$
\begin{gathered}
F_{1}=F_{2}+G . \\
F_{2}=\rho Q \beta v+\pi P_{1} r_{1}^{2}-G .
\end{gathered}
$$

In the formula, $Q$ is the runoff of the device, $\mathrm{m}^{3} / \mathrm{s} ; \rho$ is the density of water, $\mathrm{kg} / \mathrm{m}^{3}$; $V$ is the flow rate, $\mathrm{m} / \mathrm{s} ; P_{1}$ is hydrodynamic pressure, pa.

The elasticity of the spring can be ascertained by the Hooke's Law $F=k \cdot x$.

$$
k=\frac{F_{2 N}-F_{21}}{x}=\frac{\rho Q \beta v_{N}+\pi P_{N} r_{1}^{2}-\rho Q \beta v_{1}-\pi P_{1} r_{1}^{2}}{x_{\max }}
$$

\section{Flow Field Simulation of Fixed Water Distribution Device}

The structure can be improved by flow field analysis using FLUENT software. At the same time, we can compare the advantages and disadvantages with the other structures.

\subsection{Simulation of the Flow Field}

(1)Build the model by GAMBIT

GAMBIT is a high-quality pre-processor for CFD analysis which can be used to build models and generate grids. Before the CFD simulation, draw the grid figure and the boundary nodes by GAMBIT, then structured the grids, set boundary type and save the grids.

(2)Simulation the flow by FLUENT

Start the FLUENT 2D solver, read the grids file, and ascertain the unit length. Set the fluid physical properties and boundary conditions, use the standard $\kappa-\varepsilon$ onflow model and non-coupled solution method to solve the steady flow of two-dimensional space(Fujun Wang, 2005; Hongwei Wang et al.,2009). 


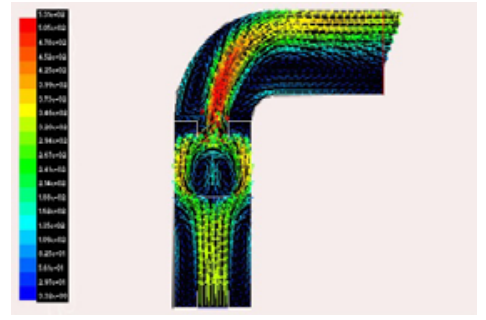

(a)

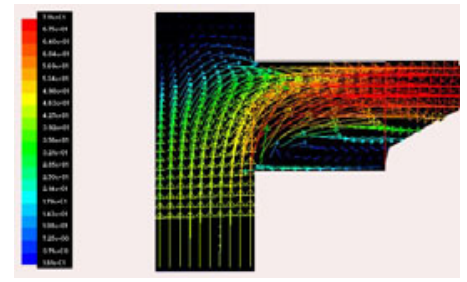

(c)

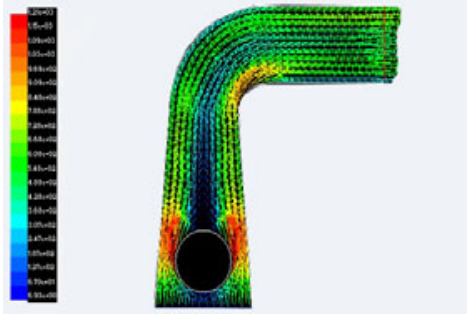

(b)
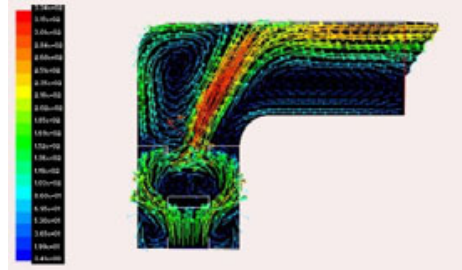

(d)

Fig. 4. Comparative analysis of flow field
(a) Sliding water distribution device
(b) Ball valve water distribution device
(c) Gland water distribution device
(d) Plate valve water distribution device

\subsection{Simulation Conclusion}

From the Fig.4, we can conclude that the ball valve water distribution device with round table had a more steady flow. The flow rate of this structure changed slightly and the fluid state was pretty well. There were many swirls in the other three structures and the flow was disordered which could not fill the pipe. We can obtain some conclusions through the simulation result:

(1)Arc-shaped bend pipe was more favorable than right angle bend pipe for the water flow steady through and keeping a stable flow field.

(2) The round table was a bundle mouth structure, which was more suitable for the fluid flow. And that played a role of steadying flow diversion, ensured the flow rate changed little, and reduced the swirl generation.

(3) The ball valve measured up to the law of liquid flow, didn't hinder the water flow. The flow can keep their original streamline with few swirls and turbulence.

\section{Computer Aided Design System of Fixed Water Distribution Device}

In order to improve the design efficiency, we compiled a design program of fixed water distribution device using Visual Basic language to meet the different irrigation conditions and different users. 


\subsection{System Development Process}

When develop a new system, we should confirm the objectives, clients and implementations first, and make the system intuitive with friendly interface, operability and flexibility. Therefore, it should make sure the development process of the system.

(1) Fixed the arrangement of the pipeline system, the distance between the water distribution devices, the device number, the pipe diameter, the runoff and other key factors.

(2) Solved the head loss of pipeline.

$$
h=1.1 \sum_{i=1}^{n} 0.948 \times 10^{5} \times \frac{(n q)^{1.77}}{d^{4.77}} \times n \times L
$$

In the formula, $d, q, l, i$ were separately the pipe diameter, single device flowrate, the distance between the water distribution devices and the device number.

(3) Solved the flow rate of every water distribution device.

$$
\begin{gathered}
H_{n}=H_{n-1}+h . \\
V_{n}=\sqrt{2 g H_{n}} .
\end{gathered}
$$

$H_{\mathrm{n}}$ is the head at the calculated device, and $V_{\mathrm{n}}$ is flow rate.

(4) Calculated the area needed for every device when they had the same flowrate.

$$
A_{n}=q / V_{n} .
$$

(5) Set the structure dimension of the device.

(6) Ascertained the position of the ball in the device. For obtaining the flow area, the ball moving distance $x$ was needed.

$$
x_{n}=h \frac{\sqrt{A_{N} / \pi}+r_{1}-r}{R-r} .
$$

(7) Analyzed the force in the ball.

$$
F_{n}=\rho q V_{n}+\pi H_{n} r_{1}^{2} .
$$

(8) Calculated the elastic coefficient.

$$
k=\frac{F_{n}-F_{1}}{h-x_{n}} .
$$

In the system, $L, n, d, q$ and $r_{1}$ were the parameters that needed to be input. 


\subsection{Operation System Design}

We programmed the design process by Visual Basic language through the analysis above. The operation interface is shown in Fig.5.

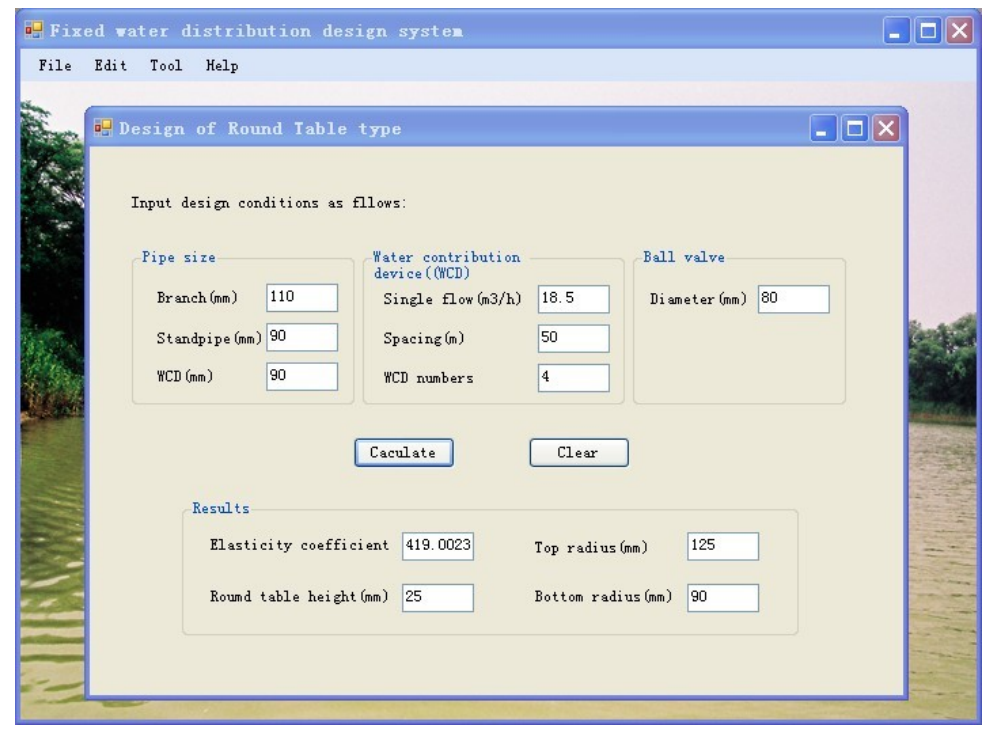

Fig. 5. Operation interface of the computer aided system

In the main program interface, input the parameters, then click the calculate button, the device dimension and the elastic coefficient of the spring will be obtained.

The operation is convenient, and the program is easy to maintain and manage. Further more, the program has the ability of extension for adding the other design modules in case it is needed.

\section{Conclusions}

(1)The structure of round table had a steady flow and low head loss proved by the flow simulation. It satisfied the design demand and adapted to the fixed distribution of pipe irrigation.

(2)The spring is the main part of the round table device, and there will be a problem with the accuracy of the device when the spring was rusted. So the structure still needs to be optimized and improved.

\section{Acknowledgements}

This research was funded by National key Technology R \& D Program of China (accession number 2006BAD11B03-02). 


\section{References}

Department of Rural Water Resources in Ministry of water resources: Engineering of pipe transmission, pp. 101-123. China water Power Press (1998) (in Chinese)

Li, Y.: Theory and technology of water saving irrigation, pp. 45-50. Wu Han Water and Hydropower University Press (1999) (in Chinese)

Xie, L., Wang, Y., Xie, Z.: Research on field engineering complement of low-pressure pipeline irrigation. Water Saving Irrigation (3) (2001) (in Chinese)

Department of Science and Education in Ministry of water resources: Transmission and irrigation technology of low-pressure pipeline, 63-72 (1991) (in Chinese)

$\mathrm{Yu}, \mathrm{S}$., Zuo, X., Zhao, W.: Water gaging status and development trend of irrigation district of china. Water Saving Irrigation (4) (2004) (in Chinese)

Li, X., Sun, F., Zhang, L.: The pipe material and fittings of pipeline irrigation system, vol. (2). Science Press (1996) (in Chinese)

Ji, Q., Shen, B., Li, G.: Research development progress of water gaging device. Irrigation and Drainage (12) (2001) (in Chinese)

Wang, C.: Application of irrigation water gaging technology of china. China Water Conservation (7) (2005) (in Chinese)

$\mathrm{He}, \mathrm{Q}$., Li, Z., Li, C.: Research on multifunction water distribution valve of low-pressure pipeline. China Rural Water and Hydropower, 24-28 (1992) (in Chinese)

Huang, Z., Zhang, Z.: Simulation and study of auto-hydrant irrigation system. Irrigation and Drainage (4) (2001) (in Chinese)

Ming, L., Xu, Q., et al.: Application research of a new autogenous pressure hydrant. China Rural Water and Hydropower (6) (2002) (in Chinese)

Huang, J., Sheng, K., Zhang, Y.: A new irrigation device of paddy field-auto-hydrant. China Rural Water and Hydropower (8) (1998) (in Chinese)

$\mathrm{Xu}, \mathrm{Z}$.: Concise guide of elastic mechanics, vol. 8. China Higher Education Press (2002) (in Chinese)

Wang, F.: Application of CFD in the turbulence analysis and performance prediction of hydraulic machinery. Journal of China Agricultural University 10(4) (2005) (in Chinese)

Wang, H., Liu, X., Liu, D.: CFD analysis of ball check valve. Fluid Transmission and Control (2) (2009) (in Chinese) 